\title{
What is a normal blood glucose?
}

Maria Güemes, Sofia A. Rahman, Khalid Hussain

Genetics and Genomic Medicine Programme, UCL Institute of Child Health and

Department of Paediatric Endocrinology, Great Ormond Street Hospital for Children

NHS, 30 Guilford Street, London, WC1N 1EH, UK.

Correspondence: Professor Khalid Hussain, Genetics and Genomic Medicine

Programme, UCL Institute of Child, 30 Guilford Street, London, WC1N 1EH UK.

Email: $\underline{\text { Khalid.Hussain@ucl.ac.uk }}$ 


\section{Summary:}

Glucose is the key metabolic substrate for tissue energy production. In the perinatal period the mother supplies glucose to the foetus and for most of the gestational period the normal lower limit of foetal glucose concentration is around $3 \mathrm{mmol} / \mathrm{L}$. Just after birth, for the first few hours of life in a normal term neonate appropriate for gestational age, blood glucose levels can range between 1.4 to $6.2 \mathrm{mmol} / \mathrm{L}$ but by about 72 hours of age fasting blood glucose levels reach normal infant, child and adult values (3.5-5.5mmol/L). Normal blood glucose levels are maintained within this narrow range by factors which control glucose production and glucose utilization. The key hormones which regulate glucose homeostasis include insulin, glucagon, adrenaline, nor-adrenaline, cortisol and growth hormone. Pathological states that affect either glucose production or utilization will lead to hypoglycaemia. Although hypoglycaemia is a common biochemical finding in children (especially in the newborn) it is not possible to define by a single (or a range of) blood glucose value/s. It can be defined as the concentration of glucose in the blood or plasma at which the individual demonstrates a unique response to the abnormal milieu caused by the inadequate delivery of glucose to a target organ (for example, the brain). Hypoglycaemia should therefore be considered as a continuum and the blood glucose concentration should be interpreted in the context of the clinical presentation, counter-regulatory hormonal responses and in relation to the intermediate metabolites. 


\section{Introduction}

Blood glucose is the most important substrate for energy production during the perinatal, neonatal and postnatal periods. Apart from the first few days of life, normal fasting blood glucose concentrations are kept within a narrow physiological range of $3.5-5.5 \mathrm{mmol} / \mathrm{L}$. Continuous blood glucose monitoring shows that blood glucose concentrations may "flicker" on either side of these two values (especially post meal) but then rapidly and spontaneously revert to within this normal range[1]. Fasting and post-prandial normal blood glucose levels are maintained within this narrow range by a complex interplay of hormones which control glucose production and glucose utilization. Glucose is produced in the liver by glycogenolysis (breakdown of stored glycogen) and gluconeogenesis (formation of glucose from noncarbohydrate sources such as lactate, alanine and glycerol). Apart from the liver, there is now evidence to show that the kidney also plays an important role as a gluconeogenic organ[2]. The key hormones which regulate glucose homeostasis include insulin, glucagon, adrenaline, noradrenaline, cortisol and growth hormone $(\mathrm{GH})$. Insulin typically regulates glucose homeostasis in the post-prandial state whereas the other hormones control blood glucose levels during the fasting state. Glucagon and adrenaline are the main line of defense against hypoglycaemia whereas cortisol and GH have a permissive role in regulating blood glucose levels.

During the perinatal period, the foetus is dependent on a continuous supply of glucose from the mother[3]. In a normal foetus there is no endogenous glucose production, however under conditions where there is reduced glucose supply, the foetus has the capability to generate glucose endogenously[4]. The rate at which the foetus undertakes glucose utilization and oxidation is determined by the maternal arterial blood glucose concentration[5].

After birth, the continuous supply of glucose to the foetus is interrupted and for the first few hours after birth, there is a transitional phase of physiologically low normal blood glucose levels 
(transitional neonatal hypoglycaemia) which normalize around 72 hours after birth. It is during these first few hours after birth that blood glucose concentrations show marked physiological variability and this represents a normal transition phase of glucose physiology.

Any pathological states which affect glucose production or utilization will lead to hypoglycaemia. In the neonatal, infancy and childhood periods, the finding of biochemical hypoglycaemia is common. However, despite the commonality of hypoglycaemia, in our current state of knowledge about glucose physiology, it is not possible to define hypoglycaemia by a particular blood glucose value/s. The brain is the key organ for glucose utilization and there is no doubt that low blood glucose levels can lead to neuronal energy deficiency and hence lead to brain injury[6]. There are no evidence based studies that define a particular blood glucose which leads to irreparable brain damage.

Having an understanding of the physiological and biochemical mechanisms that regulate normal blood glucose levels will help in the diagnostic approach to a child with hypoglycaemia. A low blood glucose level has to be interpreted in the context of the clinical scenario, the presence or absence of alternative substrates, the method used to measure blood glucose and in the neonatal period in relation to feeds. As hypoglycaemia is a common biochemical finding, making the correct diagnosis is extremely important as this will guide the clinician in patient management. Any child presenting with unexplained hypoglycaemia will need a full biochemical diagnostic work up searching for the underlying cause of the hypoglycaemia.

The aims of this review are to highlight the difficulty in defining hypoglycaemia, to describe the physiological and biochemical mechanisms that regulate blood glucose levels during the perinatal, neonatal and infancy periods and to review what "normal" blood glucose levels are during these periods. 


\section{Why is it difficult to define hypoglycaemia?}

Hypoglycaemia cannot be defined by a particular blood glucose value especially in the newborn period. The majority of appropriate for age term newborns show transient low blood glucose concentrations (transitional neonatal hypoglycaemia, discussed below) and this is a normal physiological adaptation process. Several different approaches have been used to define hypoglycaemia but none of these are satisfactory[7]. A single low blood glucose value cannot be applied universally to every individual patient.

In the newborn and infancy periods, hypoglycaemia cannot be defined by the onset of signs and symptoms as these tend to be non-specific and are not easy to recognize in this age group (unlike older children and adults). Hypoglycemic symptoms vary from being nonspecific, such as poor feeding, lethargy, and irritability, to more severe ones, like apnea, seizures, or coma. Hence, the relevance of a careful detailed clinical assessment is of the utmost importance. The responses of the brain to hypoglycaemia (neuroglycopaenic symptoms arise when insufficient glucose is available to fuel the brain) occur over a range of blood glucose levels and these responses can be modified by previous episodes (antecedent) of hypoglycaemia and by the presence of alternative brain fuels (like ketone bodies and lactate). It is not possible to define a single blood glucose value which leads to brain damage as this will depend on the frequency, severity and duration of hypoglycaemia.

In adults, clinical hypoglycaemia is defined as a blood glucose level which is low enough to cause symptoms and signs of impaired brain function[8]. Guidelines in adults emphasize the value of Whipple's triad for confirming hypoglycemia i.e., symptoms and/or signs consistent with hypoglycaemia, a documented low blood glucose concentration, and relief of signs/symptoms when blood glucose concentration is restored to normal. The same approach has been recommended for older children who are able to describe their symptoms [9]. However, this 
cannot be applied to the younger infants and of course neonates, as they cannot convey their symptoms.

When interpreting a blood glucose result, the method of collection of the blood sample will be important as some methods (especially bed side test strips) may be inaccurate. Whole blood glucose values are about $15 \%$ less compared to those in the serum and plasma. On the other hand, venous blood glucose concentrations are $10 \%$ lower than arterial. For measurement of blood glucose, blood samples should be collected into fluoride containing tubes to inhibit glycolysis.

Significant hypoglycaemia is not and can never be defined by a single number that can be applied universally to every individual patient. Rather, it is characterized by a value(s) that is unique to each individual and varies with both their state of physiologic maturity and the influence of pathology. It can be defined as the concentration of glucose in the blood or plasma at which the individual demonstrates a unique response to the abnormal milieu caused by the inadequate delivery of glucose to a target organ (for example, the brain). The "unique" response refers to the biochemical changes which are activated then the blood glucose level is lowered with/without the accompanying clinical manifestations. This response will be modulated by the availability of alternative fuels, the counter-regulatory hormonal responses and any episodes of antecedent hypoglycaemia. Thus, it is not possible to define a blood glucose level that requires intervention in every newborn infant because there is uncertainty over the level and duration of hypoglycaemia that can cause brain damage, and little is known of the vulnerability, or lack of it, of the brain of infants at different gestational ages for such damage. It is therefore clear that hypoglycaemia is a continuum and the blood glucose concentration should be interpreted in the context of the clinical presentation, counter-regulatory hormonal responses, in relation to feeds and in relation to the intermediate metabolites (fatty acids and ketone bodies). Thus, the blood 
glucose concentration has to be interpreted in the context of the clinical scenario and the presence of alternative fuels.

\section{Perinatal glucose physiology}

The mother supplies glucose to the placenta and foetus with the placenta acting as a barrier regulating the transfer of nutrients and glucose to the foetus. For placental glucose to be transported to the foetus from the maternal circulation there has to be a net maternal-to-foetal plasma glucose concentration gradient that is determined by placental as well as the foetal glucose consumption[5]. Glucose is transferred to the placenta where it is partitioned between glucose consumption by the placenta and that transferred to the foetus.

Glucose is taken up from the maternal plasma by the GLUT 1 transporter protein and transported to the foetus by facilitative diffusion according to concentration-dependent kinetics[10]. GLUT 1 is the main glucose transporter protein isoform in maternal-facing microvillus and foetal-facing syncytiotrophoblast membranes. The increase in the surface area and the maintenance of a high GLUT 1 density accounts for the increase in placental glucose transport in the latter part of pregnancy[11]. Studies in sheep have shown that in the second half of pregnancy, foetal glucose demand grows much more rapidly (about a 10 fold increase) than placental glucose transfer capacity and this then requires a decrease in foetal glucose concentration to balance glucose supply and demand[12]. The increased glucose transport leads to significant deposition of glycogen and fat stores, especially in the third trimester.

\section{Blood glucose values in the normal foetus}

The foetus consumes glucose as its principle metabolic fuel for energy production. The foetal glucose concentration is a function of both gestational age and the maternal glucose concentration. At around 20 weeks of gestational age there is a linear relationship between maternal and foetal glucose concentrations[13]. For most of the gestational period (and 
especially after 20 weeks) the foetus is exposed to circulating glucose concentrations only slightly below those of maternal plasma. With a normal maternal glucose concentration of 3.5$5.5 \mathrm{mmol} / \mathrm{L}$, the mean foetal-maternal plasma glucose difference at term is only $0.5 \mathrm{mmol} / \mathrm{L}$, thus in the term healthy foetus the normal glucose concentration is around $3 \mathrm{mmol} / \mathrm{L}[3]$.

Glucose contributes nearly to $80 \%$ of the total energy requirement of the foetus and the remaining $20 \%$ of foetal energy needs is provided by lactate, amino acids and glycerol[14]. The foetus utilizes glucose at a higher rate than that observed in adults $(5-7 \mathrm{mg} / \mathrm{kg} / \mathrm{min}$ vs 2$3 \mathrm{mg} / \mathrm{kg} / \mathrm{min}$ ). Under normal conditions there is no foetal glucose production (by glycogenolysis or gluconeogenesis), but glucose production is stimulated in the foetus exposed to prolonged periods of low glucose supply (for example during fasting or placental insufficiency). Glycogenic enzymes are present in foetal liver as early as 8 weeks of gestation and the hepatic glycogen content increases from $3.4 \mathrm{mg} / \mathrm{g}$ at 8 weeks of gestation to $50 \mathrm{mg} / \mathrm{g}$ at term.

Insulin is the main anabolic hormone in foetal life and islet pancreatic beta-cells can be detected in the pancreas as early as 10-12th weeks of gestation[15]. Foetal pancreatic beta-cells release insulin poorly in response to changes in the blood glucose concentration and the response to a glucose load is blunted. Insulin becomes detectable around 10-12 weeks of gestation in the foetus and during the perinatal period insulin is more important for regulating growth rather than regulating glucose metabolism.

\section{Glucose physiology in the normal term neonate: making the transition to an independent existence}

At birth the healthy term newborn must adapt to an independent existence. The transplacental supply of nutrients including glucose is interrupted and the newborn must now initiate metabolic and endocrine responses to maintain adequate circulating blood glucose concentrations. For extrauterine adaptation there must be adequate glycogen stores, intact and functional 
glycogenolytic, gluconeogenic, lipogenic and ketogenic mechanisms and appropriate counterregulatory hormonal responses. Figure 1 shows the metabolic, endocrine and physiological changes which occur at the time of birth to allow a normal term newborn to adapt to an independent existence.

An appropriate for gestational age normal infant shows an immediate postnatal fall (physiologically normal) in blood glucose concentrations during the first 2-4 hours of life. During this transitional phase, "normal" blood glucose values can range from as low as $1.4 \mathrm{mmol} / \mathrm{L}$ to as high as $6.2 \mathrm{mmol} / \mathrm{L}[16,17]$. The lowest mean blood glucose documented within the first few hours of birth can be as low as $2.3 \mathrm{mmol} / \mathrm{L}[18]$. Studies that have documented "normal" blood glucose concentrations in healthy, appropriate for gestational age newborns in the first hours of life are listed in table 1 [16 - 23].

Healthy term breastfed babies have significantly lower blood glucose concentrations (mean 3.6mmol/l; range 1.5-5.3), than those who are bottle-fed (mean 4.0mmol/l; range 2.5-6.2), but their ketone body concentrations are elevated in response to breast feeding[17, 23]. Figure 2 shows the results of a study [23] with the serial mean and +/-SD plasma glucose levels within the first 72 hours of life in exclusively breast fed infants and Figure 3 shows the distribution of these blood glucose levels.

In addition to the low blood glucose levels, the serum insulin concentrations are inappropriately high during this transitional phase of normal glucose physiology, suggesting a transient alteration in the set point for insulin secretion during this period [24, 25]. However, despite the marked variability in the blood glucose levels and transient alteration in the set point for insulin secretion during the first few hours of life, after about 72 hours of age, all term healthy newborns reach fasting blood glucose levels comparable to those of children and adults (3.5-5.5mmol/L). The above endocrine and metabolic profiles observed in appropriate for gestational age normal 
infants in the first a few days of life suggest that these are relatively low blood glucose levels in comparison to older babies where the glucose set point for suppression of insulin secretion is reduced[25].

The drop in the glucose levels noted after birth appears essential to facilitate physiological transition for neonatal survival, which includes increased glucose production by glycogenolysis, gluconeogenesis, stimulation of appetite, adaptation to fast/feed cycles, and promotion of oxidative fat metabolism using lipid from fat stores and ingested milk feeds[26]. The trigger for the metabolic and endocrine adaptation with reference to glucose control is unclear, but surges in catecholamines and glucagon secretion are thought to be important. The raised plasma insulin to glucagon ratio is reversed at birth allowing glucagon to activate adenylate cyclase and increase the activity of cAMP-dependent protein kinase $A(P K A)$. This in turn, activates phosphorylase kinase which facilitates glucose release into the circulation.

The catecholamine surge and an increase in TSH (thyroid stimulating hormone) activates lipolysis and lipid oxidation, resulting in increases in the levels of glycerol and free fatty acids[27]. Free fatty acids are transported to the liver to generate ketone bodies which are used as an alternative source of fuel. Major changes occur in the function of several physiological systems after birth which enables the neonate to adapt to postnatal nutrition. Successful enteral feeding in healthy term newborns triggers the secretion of gut peptides and plays a key role in triggering a cascade of developmental changes in gut structure and function, and in the relation of pancreatic endocrine secretion to intermediary metabolism[28].

Hence, full-term infants are functionally and metabolically programmed to make the transition from their intrauterine dependent environment to their extra-uterine existence without the need for metabolic monitoring or interference with the natural breastfeeding process. This complex 
metabolic and endocrine adaptation process is incomplete and compromised when the infant is born prematurely or following intrauterine growth retardation.

\section{Maintenance of a normal blood glucose level: Integration of the physiological changes associated with feeding and fasting.}

Normal fasting blood glucose levels in infants, children and adults are maintained within a narrow range (3.5-5.5mmol/L) despite the frequent feed and fasting cycles. Insulin plays a major role in regulating glucose production and utilization during both the fed and fasted state.

Following the ingestion of a meal, the plasma glucose concentration starts to increase within 15 minutes[29]. This increase in the plasma glucose level and the stimuli from neurogenic and entero-insular axis (gastric inhibitory peptide (GIP) and glucagon-like peptide 1 (GLP-1)) stimulates insulin secretion from the pancreatic beta-cells. Peak levels of plasma glucose are reached around 30-60 minutes following ingestion after which it starts to decrease until absorption is complete, usually about 4-5 hours later, with plasma insulin concentrations following a similar time course.

Following the ingestion of a meal, there is a marked suppression of endogenous glucose production from the liver, the magnitude of which is largely determined by the insulin and glucagon responses[30]. Endogenous glucose production may be suppressed up to 50-60\% with about 25 grams less glucose being delivered into the systemic circulation[31].

Postprandially, plasma glucose levels are determined by a balance between the rates of glucose removal from the systemic circulation and the rate of delivery of glucose into the systemic circulation. Also, postprandially the processes of glycogenolysis, gluconeogenesis, lipolysis and ketogenesis are all suppressed. The tissues mainly responsible for the removal of glucose from the systemic circulation include the liver, small intestine, brain, muscle and 
adipose tissue. The magnitude of glucose uptake by the tissues, except for the brain, is largely determined by the plasma insulin concentration. Glucose uptake by the brain is determined by the plasma glucose concentration and is independent of the plasma insulin concentration.

The 4-6 hours interval following the ingestion of a meal is sometimes referred to as the post absorptive state. During this interval, a steady state is reached whereby glucose production is equal to the rate of glucose consumption and plasma glucose concentrations are maintained within a normal range. During this state, it is estimated that glucose turnover (glucose production and utilization) is approximately $10 \mathrm{micromol} / \mathrm{kg} / \mathrm{min}[32]$. In this state, non-insulin dependent utilization of glucose accounts for $80 \%$, mainly by the brain (which accounts for $50 \%$ of the total), red blood cells, kidneys and the gastro-intestinal system. During this phase, glucose concentrations are maintained by interactions between insulin and the various counterregulatory hormones including glucagon, cortisol, GH, adrenaline and nor-adrenaline. Glucagon allows the controlled release of stored glycogen from the liver and insulin restrains the effects of glucagon by preventing accelerated lipolysis and proteolysis. The counter-regulatory hormones including cortisol and GH play permissive roles in setting the sensitivity of the peripheral tissues to glucagon and insulin.

As the period of the fast is lengthened, utilization of glucose by the tissues decreases while utilization of free fatty acids and ketone bodies increases[33]. There is a reduction in hepatic glucose output, which is accounted for mainly by a decrease in glycogenolysis, with an increase in the rate of gluconeogenesis. The increased gluconeogenesis is thought to be related to the increased secretion of glucagon and other counter-regulatory hormones, as well as the reduction in insulin secretion. The increased glucagon secretion is associated with reduced insulin secretion allowing stored fats to be converted to glycerol and fatty acids and proteins to be converted to amino acids for gluconeogenesis. The liberated free fatty acids are transported 
to the liver bound to albumin, where they can either undergo beta-oxidation in the mitochondria or be re-esterified to triacylglycerol's and phospholipids. The process of beta-oxidation yields acetyl-Co which can then be converted to ketone bodies, acetoacetate and $3 \beta$-hydroxybutyrate, via the hydroxymethylglutaryl-CoA (HMG-CoA) pathway, or it can undergo complete oxidation in the tricarboxylic acid cycle.

The major gluconeogenic precursors after an overnight fast are lactate, glycerol and alanine. The majority of the lactate and alanine generated after an overnight fast originate from plasma glucose and represent recycling of carbon atoms. The first reaction in gluconeogenesis involves the conversion of pyruvate to oxaloacetate to phosphoenolpyruvate. The second of these reactions converts fructose-1, 6-biphosphate to fructose-6-biphosphate. This is the ratelimiting step for the process of gluconeogenesis. The final step involves the conversion of glucose-6-phosphate to free glucose.

Young children differ from adults in that they have limited glycogen stores which are only adequate for a period of starvation of approximately 12 hours after which the maintenance of a normal blood glucose concentration is dependent on gluconeogenesis. Haymond et al[34] showed that children fasted for 30 hours and had the lowest glucose and alanine concentrations as compared to adult men and women. For this reason, children are unable to tolerate prolonged periods of starvation.

Children have higher glucose production rates in comparison to adults in order to meet the increased metabolic demands of the brain that, relative to body size, is much larger than in adults. Bier et al[35] measured glucose production rates in infants and children using 6,6-dideuteroglucose and showed that the brain size was the principal determinant of factors that regulate hepatic glucose output throughout life. 
Sunehag et al[36] have shown that the rate of gluconeogenesis, on a body weight basis, is greater in children between the ages of 8 and 9 years than in adolescents between the ages of 14 and 16 years, whereas the fraction of glucose production derived from gluconeogenesis was essentially identical between the two groups of subjects. The same study showed that gluconeogenesis contributed to $50 \%$ of glucose production in the childhood period. The fasting newborn and young children demonstrate a high glucose utilization rate per kilogram body weight relative to adult requirements. Hence for these reasons, children are more susceptible to hypoglycaemia in comparison to adults.

Muscle and other tissues become progressively more dependent on free fatty acids and ketone bodies for their continued energy requirements as the period of the fast is prolonged. Ketone bodies are produced in the liver, mainly from the oxidation of fatty acids, and are exported to peripheral tissues for use as an energy source. They are particularly important for the brain, which has no other substantial non-glucose-derived energy source. Ketone bodies replace glucose as the predominant fuel for nervous tissue, thereby reducing the obligatory requirement of the brain[37].

During the period of a fast there is a complex interaction of metabolic and hormonal mechanisms, which produces significant variations in the concentrations of the counterregulatory hormones and intermediary metabolites. Children differ in their response to fasting in comparison to adults[34]. For example, studies in adults have shown that the levels of free fatty acids, glycerol, and ketones in the blood gradually increase as the period of starvation is extended[38]. During a brief period of fasting in the childhood period, ketosis and ketonuria develop readily, suggesting that children convert more rapidly to a fuel economy based largely on fat. Thus infants and children develop hypoglycaemia more readily. 


\section{Conclusions}

Apart from the immediate neonatal period, the normal range of fasting blood glucose concentration is $3.5-5.5 \mathrm{mmol} / \mathrm{L}$. Blood glucose concentrations are kept within this range by a complex interplay of hormones which control glucose production and utilization. In term appropriate for age healthy newborns within the first few hours of life, "normal" blood glucose concentrations can range between 1.4 to $6.2 \mathrm{mmol} / \mathrm{L}$, but by about 72 hours of life they reach values of $3.5-5.5 \mathrm{mmol} / \mathrm{L}$. Hypoglycaemia should be considered as a continuum and the blood glucose concentration should be interpreted in the context of the clinical presentation, counterregulatory hormonal responses and in relation to the intermediate metabolites. 


\section{Legends}

Figure 1: The metabolic, endocrine and the physiological changes which occur at the time of birth to allow a normal term newborn to adapt to an independent existence.

Table 1: Studies that have published "normal" blood glucose concentrations (BM) in healthy, appropriate for gestational age (AGA) newborns in the first hours of life.

Figure 2: Plasma glucose concentrations measured serially in 200 term appropriate size for gestational age and exclusively breast-fed infants, at 3, 6, 24 and 72 hours of age (adapted from[23]).

Figure 3: Plasma glucose concentration distribution at the time of sampling in 200 term appropriate size for gestational age and exclusively breast-fed infants, at 3, 6, 24 and 72 hours of age (adapted from[23]). 


\section{References}

1. Kaufman FR. Role of the continuous glucose monitoring system in pediatric patients.

Diabetes Technol Ther. 2000;2 Suppl 1:S49-52

2. Mitrakou A. Kidney: its impact on glucose homeostasis and hormonal regulation. Diabetes Res Clin Pract. 2011 Aug;93 Suppl 1:S66-72.

3. Kalhan SC, D’Angelo L, Savin SM, et al. Glucose production in pregnant women at term gestation: Sources of glucose for human fetus. J Clin Invest 1979;63:388-94

4. DiGiacomo JE, Hay WW Jr. Fetal glucose metabolism and oxygen consumption during sustained hypoglycemia. Metabolism. 1990 Feb;39(2):193-202

5. Hay WW Jr. Regulation of placental metabolism by glucose supply. Reprod Fertil Dev. $1995 ; 7(3): 365-75$.

6. Burns CM, Rutherford MA, Boardman JP, et al. Patterns of cerebral injury and neurodevelopmental outcomes after symptomatic neonatal hypoglycemia. Pediatrics. 2008 Jul;122(1):65-74. doi: 10.1542/peds.2007-2822.

7. Cornblath M, Hawdon JM, Williams AF, et al. Controversies regarding definition of neonatal hypoglycemia: suggested operational thresholds. Pediatrics. 2000 May;105(5):1141-5.

8. Cryer PE, Axelrod L, Grossman AB, et al. Evaluation and management of adult hypoglycemic disorders: an Endocrine Society Clinical Practice Guideline. J Clin Endocrinol Metab 2009;94(3):709-28.

9. Thornton PS, Stanley CA, De Leon DD, et al. Recommendations from the Pediatric Endocrine Society for Evaluation and Management of Persistent Hypoglycemia in Neonates, Infants, and Children. J Pediatr. 2015 May 6. pii: S0022-3476(15)00358-3.

10. Hay WW Jr. Placental transport of nutrients to the fetus. Horm Res. 1994;42(4-5):215-22 11. Jansson T, Wennergren M, Illsley NP. Glucose transporter protein expression in human placenta throughout gestation and in intrauterine growth retardation. J Clin Endocrinol Metab. 1993 Dec;77(6):1554-62. 
12. Molina RD, Meschia G, Battaglia FC, et al. Gestational maturation of placental glucose transfer capacity in sheep. Am J Physiol. 1991 Sep;261(3 Pt 2):R697-704.

13. Bozzetti $P$, Ferrari MM, Marconi AM, et al. The relationship of maternal and fetal glucose concentrations in the human from midgestation until term. Metabolism. 1988 Apr;37(4):358-63.

14. Rao PN, Shashidhar A, Ashok C. In utero fuel homeostasis: Lessons for a clinician. Indian J Endocrinol Metab. 2013 Jan;17(1):60-8.

15. Piper K, Brickwood S, Turnpenny LW, et al. Beta-cell differentiation during early human pancreas development. Journal of Endocrinology. 2004;181:11-23.

16. Hoseth E, Joergensen A, Ebbesen F, et al. Blood glucose levels in a population of healthy, breast fed, term infants of appropriate size for gestational age. Arch Dis Child Fetal Neonatal Ed. 2000 Sep;83(2):F117-9

17. Hawdon, JM, Ward-Platt MP, Aynsley-Green A. Patterns of metabolic adaptation for preterm and term infants in the first neonatal week. Arch Dis Child 1992;67:357-65.

18. Sweet DG, Hadden D, Halliday HL. The effect of early feeding on the neonatal blood glucose level at 1-hour of age. Early Hum Dev. 1999;55(1):63-6.

19. Acharya PT, Payne WW. Blood Chemistry of Normal Full-Term Infants in the First 48 Hours of Life. Arch Dis Child. 1965;40:430-5.

20. Srinivasan G, Pildes RS, Cattamanchi G, et al. Plasma glucose values in normal neonates: a new look. J Pediatr. 1986;109(1):114-7.

21. Heck LJ, Erenberg A. Serum glucose levels in term neonates during the first 48 hours of life. J Pediatr. 1987;110(1):119-22.

22. Dollberg S, Bauer R, Lubetzky R, et al. A reappraisal of neonatal blood chemistry reference ranges using the Nova M electrodes. Am J Perinatol. 2001;18(8):433-40.

23. Diwakar KK, Sasidhar MV. Plasma glucose levels in term infants who are appropriate size for gestation and exclusively breast fed. Arch Dis Child Fetal Neonatal Ed. 2002;87(1):F46-8. 24. Hawdon JM, Aynsley-Green A, Alberti KG, et al. The role of pancreatic insulin secretion in neonatal glucoregulation. Healthy term and preterm infants. Arch Dis Child 1993;68:274-9 
25. Stanley CA, Anday EK, Baker L, et al. Metabolic fuel and hormone responses to fasting in newborn infants. Pediatrics 1979;64:613-9

26. Stanley CA, Rozance PJ, Thornton PS, et al. Re-evaluating "transitional neonatal hypoglycemia": mechanism and implications for management. J Pediatr. 2015 Jun;166(6):15201525.e1.

27. Sperling MA, Ganguli S, Leslie N, et al. Fetal-perinatal catecholamine secretion: role in perinatal glucose homeostasis. Am J Physiol. 1984 Jul;247(1 Pt 1):E69-74.

28. Aynsley-Green A, Lucas A, Lawson GR, et al. Gut hormones and regulatory peptides in relation to enteral feeding, gastroenteritis, and necrotizing enterocolitis in infancy. $J$ Pediatr. 1990 Jul;117(1 Pt 2):S24-32.

29. Mitrakou A, Kelley D, Veneman T, et al. Contribution of abnormal muscle and liver glucose metabolism to postprandial hyperglycemia in NIDDM. Diabetes. 1990 Nov;39(11):1381-90. 30. Mitrakou A, Vuorinen-Markkola H, Raptis G, et al. Simultaneous assessment of insulin secretion and insulin sensitivity using a hyperglycemia clamp. J Clin Endocrinol Metab. 1992 Aug;75(2):379-82.

31. Firth RG, Bell PM, Marsh HM, et al. Postprandial hyperglycemia in patients with noninsulindependent diabetes mellitus. Role of hepatic and extrahepatic tissues. J Clin Invest. 1986 May;77(5):1525-32.

32. Bolli GB, Gottesman IS, Cryer PE, et al. Glucose counterregulation during prolonged hypoglycemia in normal humans. Am J Physiol. 1984 Aug;247(2 Pt 1):E206-14.

33. Fukao T, Mitchell G, Sass JO, et al. Ketone body metabolism and its defects. J Inherit Metab Dis. 2014 Jul;37(4):541-51.

34. Haymond MW, Karl IE, Clarke WL, et al. Differences in circulating gluconeogenic substrates during short-term fasting in men, women, and children. Metabolism. 1982 Jan;31(1):33-42.

35. Bier DM, Leake RD, Haymond MW, et al. Measurement of "true" glucose production rates in infancy and childhood with 6,6-dideuteroglucose. Diabetes. 1977 Nov;26(11):1016-23. 
36. Sunehag AL, Treuth MS, Toffolo G, et al. Glucose production, gluconeogenesis, and insulin sensitivity in children and adolescents: an evaluation of their reproducibility. Pediatr Res. 2001 Jul;50(1):115-23.

37. Zhang Y, Kuang Y, Xu K, et al. Ketosis proportionately spares glucose utilization in brain. $J$ Cereb Blood Flow Metab. 2013 Aug;33(8):1307-11.

38. Cahill GF Jr. Starvation in man. Clin Endocrinol Metab. 1976 Jul;5(2):397-415. 
Table 1

\begin{tabular}{|c|c|c|c|c|c|c|}
\hline $\begin{array}{l}\text { Publication } \\
\text { Author, year } \\
\text { [Reference] }\end{array}$ & Study size (n) & $\begin{array}{l}\text { Age (hours } \\
\text { of life) }\end{array}$ & $\begin{array}{l}\text { BM in } \mathrm{mmol} / \mathrm{l}, \\
\text { Mean } \pm \mathrm{SD}^{¥} \\
(\text { range })^{*}\end{array}$ & $\begin{array}{l}\text { Feeding mode when } \\
\text { sampled }\end{array}$ & Subjects' characteristics & $\begin{array}{l}\text { Study design } \\
\text { Method of analysis }\end{array}$ \\
\hline \multirow{12}{*}{$\begin{array}{l}\text { Acharya and Payne, } \\
1965 \text { (19) }\end{array}$} & 14 & 0 & $\begin{array}{l}4.0 \pm 0.9 \\
(2.5-5.3)\end{array}$ & \multirow{12}{*}{ Not specified } & \multirow{12}{*}{$\begin{array}{l}\text { Term, AGA, no maternal or } \\
\text { neonatal complications }\end{array}$} & \multirow{12}{*}{$\begin{array}{l}\text { Nelson-Somogyi } \\
\text { photometric assay [assay also } \\
\text { measures other reducing sugars] }\end{array}$} \\
\hline & 14 & 1 & $\begin{array}{l}3.5 \pm 1.1 \\
(1.7-5.9)\end{array}$ & & & \\
\hline & 14 & 2 & $\begin{array}{l}3.3 \pm 1.0 \\
(1.7-5.2)\end{array}$ & & & \\
\hline & 14 & 3 & $\begin{array}{l}3.5 \pm 1.1 \\
(2.2-6.2)\end{array}$ & & & \\
\hline & 14 & 5 & $\begin{array}{l}3.5 \pm 1.2 \\
(2.2-5.4) \\
\end{array}$ & & & \\
\hline & 14 & 7 & $\begin{array}{l}3.3 \pm 1.1 \\
(1.9-4.9)\end{array}$ & & & \\
\hline & 14 & 9 & $\begin{array}{l}3.3 \pm 0.8 \\
(1.8-4.9)\end{array}$ & & & \\
\hline & 14 & 11 & $\begin{array}{l}3.6 \pm 1.5 \\
(2.3-7.9) \\
\end{array}$ & & & \\
\hline & 14 & 18 & $\begin{array}{l}3.5 \pm 0.9 \\
(2.3-5.8)\end{array}$ & & & \\
\hline & 14 & 24 & $\begin{array}{l}3.2 \pm 0.8 \\
(1.6-4.3)\end{array}$ & & & \\
\hline & 14 & 36 & $\begin{array}{l}3.1 \pm 0.9 \\
(1.6-5.0)\end{array}$ & & & \\
\hline & 14 & 48 & $\begin{array}{l}3.3 \pm 0.7 \\
(2.2-5.0)\end{array}$ & & & \\
\hline \multirow{3}{*}{$\begin{array}{l}\text { Srinivasan et al, } \\
1986(20)\end{array}$} & 52 & 1 & $\begin{array}{c}3.11 \pm 1.06 \\
(0.9-6.6)\end{array}$ & \multirow{3}{*}{ Not fed } & \multirow{3}{*}{$\begin{array}{l}\text { Full term, AGA ( } 2.5-4.0 \mathrm{Kg}) \text {, no } \\
\text { maternal or neonatal } \\
\text { complications }\end{array}$} & \multirow{3}{*}{ Beckman glucose oxidase analyzer } \\
\hline & 52 & 2 & $\begin{array}{l}3.33 \pm 0.61 \\
(2.17-5.33)\end{array}$ & & & \\
\hline & 51 & 3 & $\begin{array}{c}3.89 \pm 0.72 \\
(2.2-5.4) \\
\end{array}$ & & & \\
\hline \multirow{2}{*}{$\begin{array}{l}\text { Heck and Erenberg, } \\
1987(21)\end{array}$} & 113 & 1 & $3.33 \pm 1.00$ & \multirow{2}{*}{ Not fed } & \multirow{2}{*}{$\begin{array}{l}\text { Term ( } 37-42 \text { weeks), no } \\
\text { maternal or neonatal } \\
\text { complications }\end{array}$} & \multirow{2}{*}{$\begin{array}{c}\text { Longitudinal } \\
\text { Beckman glucose oxidase analyzer }\end{array}$} \\
\hline & 107 & 2 & $3.39 \pm 0.83$ & & & \\
\hline \multirow{11}{*}{$\begin{array}{l}\text { Hawdon et al, } 1992 \\
\text { (17) }\end{array}$} & 9 NVD & 0 & 4.3 & \multirow{11}{*}{ Breast or formula } & \multirow{11}{*}{$\begin{array}{l}\text { Term ( }>37 \text { weeks), AGA, white } \\
\text { ethnicity, born by NVD or C- } \\
\text { section, no maternal or } \\
\text { neonatal complications }\end{array}$} & \multirow{11}{*}{$\begin{array}{l}\text { Cross-sectional } \\
\text { Cobas fast centrifugal } \\
\text { analyser }\end{array}$} \\
\hline & 24 C-section & 0 & 3.4 & & & \\
\hline & $11 \mathrm{NVD}$ & $1-12$ & 3.1 & & & \\
\hline & $11 \mathrm{C}$-section & $1-12$ & 3.3 & & & \\
\hline & $9 \mathrm{NVD}$ & $12-24$ & 3.7 & & & \\
\hline & $10 \mathrm{C}$-section & $12-24$ & 3.3 & & & \\
\hline & 27 & Day 2 & 3.5 & & & \\
\hline & 27 & Day 3 & 3.4 & & & \\
\hline & 21 & Day 4 & 4.1 & & & \\
\hline & 20 & Day 5 & 4.0 & & & \\
\hline & 20 & Day 6 & 4.2 & & & \\
\hline \multirow{3}{*}{ Sweet et al, 1999 (18) } & 22 & 1 & $2.34 \pm 0.91$ & Breast & \multirow{3}{*}{$\begin{array}{c}\text { Babies }>37 \text { weeks, normal } \\
\text { Apgars, not admitted to NICU, } \\
\text { no maternal diabetes }\end{array}$} & \multirow{3}{*}{$\begin{array}{c}\text { Cross-sectional } \\
\text { HemoCue B-Glucose system }\end{array}$} \\
\hline & 24 & 1 & $2.52 \pm 0.84$ & Formula & & \\
\hline & 29 & 1 & $2.58 \pm 0.94$ & Not fed & & \\
\hline \multirow{2}{*}{$\begin{array}{l}\text { Hoseth et al, } \\
2000 \text { (16) }\end{array}$} & 22 & 1 & $\begin{array}{l}2.9 \pm 0.7 \\
(1.4-4.0)\end{array}$ & \multirow{2}{*}{ Breast } & \multirow{2}{*}{$\begin{array}{l}\text { Term ( } 37-42 \text { weeks), AGA, } \\
\text { normal Apgars, no maternal } \\
\text { or neonatal complications }\end{array}$} & \multirow{2}{*}{$\begin{array}{c}\text { Cross-sectional } \\
\text { Glucose dehydrogenase } \\
\text { photometric } \\
\text { method }\end{array}$} \\
\hline & 27 & 2 & $\begin{array}{l}3.2 \pm 0.8 \\
(2.0-4.9)\end{array}$ & & & \\
\hline $\begin{array}{l}\text { Dollberg et al, } 2001 \\
\qquad(22)\end{array}$ & 50 & $2-4$ & $\begin{array}{c}3.97 \pm 0.76^{*} \\
(1.8-5.8)\end{array}$ & Not specified & $\begin{array}{c}\text { Term ( } 38-41 \text { weeks), AGA, } \\
\text { normal Apgars, no maternal } \\
\text { or neonatal complications }\end{array}$ & $\begin{array}{c}\text { Cross-sectional } \\
\text { Nova Stat } \\
\text { Profile M glucose oxidase electrode }\end{array}$ \\
\hline \multirow{4}{*}{$\begin{array}{l}\text { Diwakar and Sasidhar, } \\
\qquad 2002(23)\end{array}$} & \multirow{4}{*}{200} & 3 & $\begin{array}{c}3.0 \pm 1.05 \\
(1.4-8.3) \\
\end{array}$ & \multirow{4}{*}{ Fed and not fed } & & \\
\hline & & 6 & $\begin{array}{c}2.95 \pm 0.75 \\
(1.6-5.4) \\
\end{array}$ & & Term ( $37-42$ weeks), AGA, & Longitudinal \\
\hline & & 24 & $\begin{array}{c}2.89 \pm 0.79 \\
(1.3-7.6) \\
\end{array}$ & & $\begin{array}{l}\text { normal Apgars, no maternal } \\
\text { or neonatal complications }\end{array}$ & Hitachi 902 Nova Biomedical Corp \\
\hline & & 72 & $\begin{array}{l}3.0 \pm 0.79 \\
(1.4-7.1)\end{array}$ & & & \\
\hline
\end{tabular}

BM: Blood glucose concentration. AGA: Appropriate size for gestational age. NVD: Normal vaginal delivery. C-section: Caesarean section. NICU:

Neonatal intensive care unit.

$¥$ When available

*Whole blood values reported using Nova Stat were adjusted to plasma glucose values using a correction factor of 1.135 
Figure 2

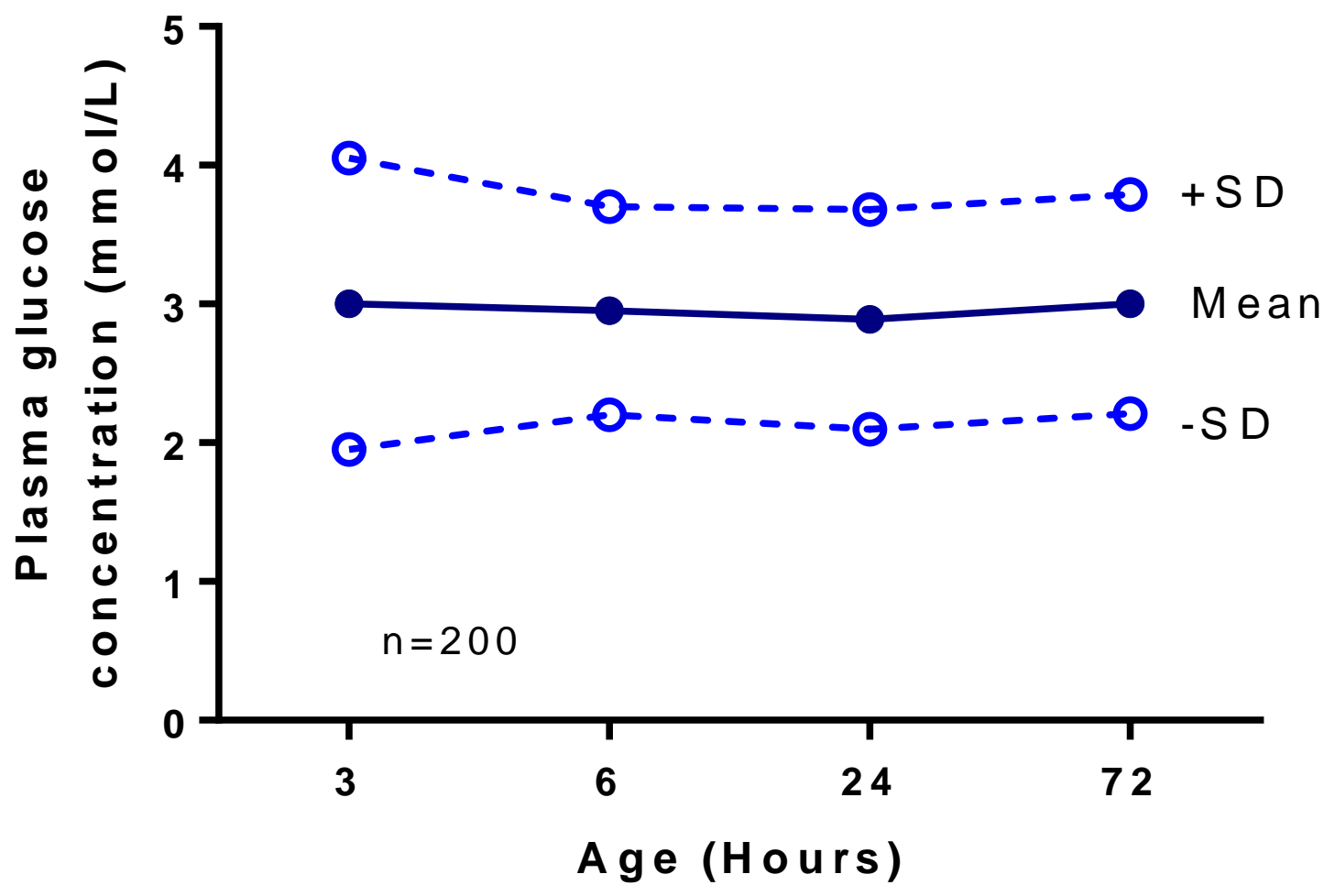


Figure 3

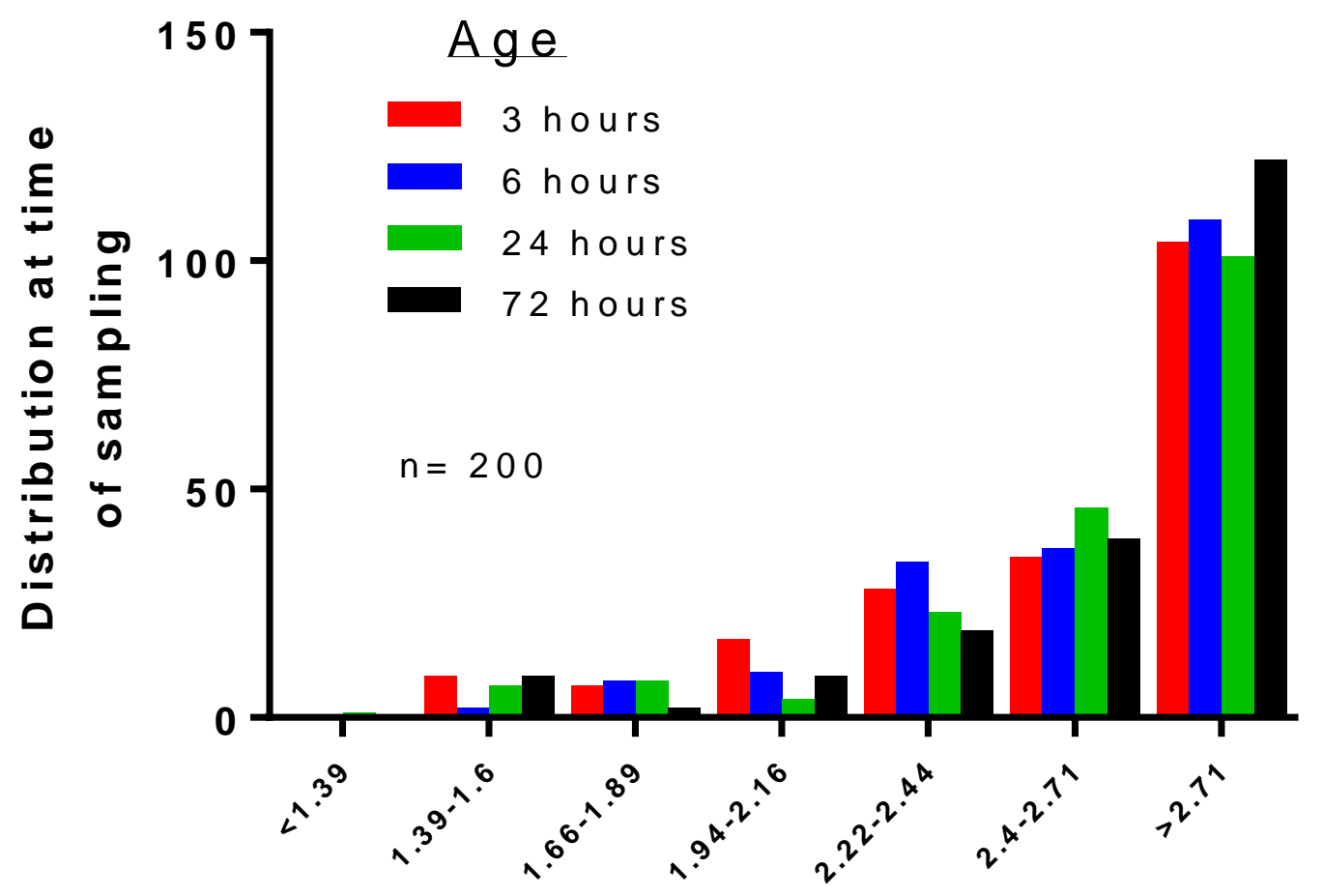

Plasma glucose concentration ( $\mathrm{mmol} / \mathrm{L}$ ) 